\title{
THE EFFECTS OF CONTINUOUS POSITIVE PRESSURE VENTILATION ON PULMONARY OEDEMA, GAS EXCHANGE AND LUNG MECHANICS
}

\author{
Jtri Obdrzalek, J. Colin Kay, and William H. Noble
}

\section{INTRODUCTION}

CONTINUOUS POSITIVE PRESSURE vENTILATION (CPPV) has been successfully used for the treatment of hypoxaemia in a clinical syndrome which is characterized by a stiff lung, coalescent densities on X-ray and a high degree of pulmonary shunt. This syndrome is caused by interstitial or interalveolar oedema. Conventional therapy with diuretics, digitalis and oxygen is not always successful and the outcome is often fatal. ${ }^{1-3}$ When CPPV is applied, shunt and arterial oxygen tension significantly improve, coalescent densities on X-ray disappear and the lung again becomes compliant. ${ }^{1-7}$

The mechanism by which the CPPV improves pulmonary function is not known. Some investigators ${ }^{1,2}$ believe that CPPV opens atelectatic alveoli but atelectactic units have not been demonstrated in oedema. ${ }^{8}$ Others suggest that high airway pressure facilitates reabsorption of oedema back into the pulmonary circulation. ${ }^{1-4}$ Improvement of the X-ray picture, pulmonary compliance and shunt seem to support this hypothesis. However, the instantaneous character of these changes, ${ }^{1-3}$ as well as the rapid reappearance of respiratory failure after withdrawal of $\mathrm{CPPV}^{2,3,22}$ suggests that oedema is still present within the lung. This controversy could not be satisfactorily settled until a reliable method was available for rapid sequential assessment of oedema in vivo. Using a new thermodilution method" we followed small changes in lung extravascular water. This enabled us to demonstrate the effect of CPPV on the development of oedema in a rapidly changing clinical situation. Correlation between the gross appearance of the lung and changing compliance and shunt cast some further light on the mechanism by which CPPV improved lung function.

\section{Methods}

Twenty-three mongrel dogs were anaesthetized with I.V. Pentobarbital (20-25 $\mathrm{mg} / \mathrm{kg}$ ), additional doses were given during the experiment to keep the dog unconscious. The dogs were tracheostomized and thermodilution catheters were inserted into the pulmonary artery through the jugular vein and into the aortic arch through the right carotid artery. The positions of the catheters were verified by pressure tracings in vivo and by autopsy. A balloon was placed into the oesophagus $^{10}$ to monitor pleural pressure. The dogs were placed supine in a plethysmograph

Department of Anaesthesia, St. Michael's Hospital and University of Toronto, Toronto, Ontario, Canada.

An abstract from this paper was presented at the Canadian Anaesthetists' Society Annual Meeting in Halifax, in 1972 . 


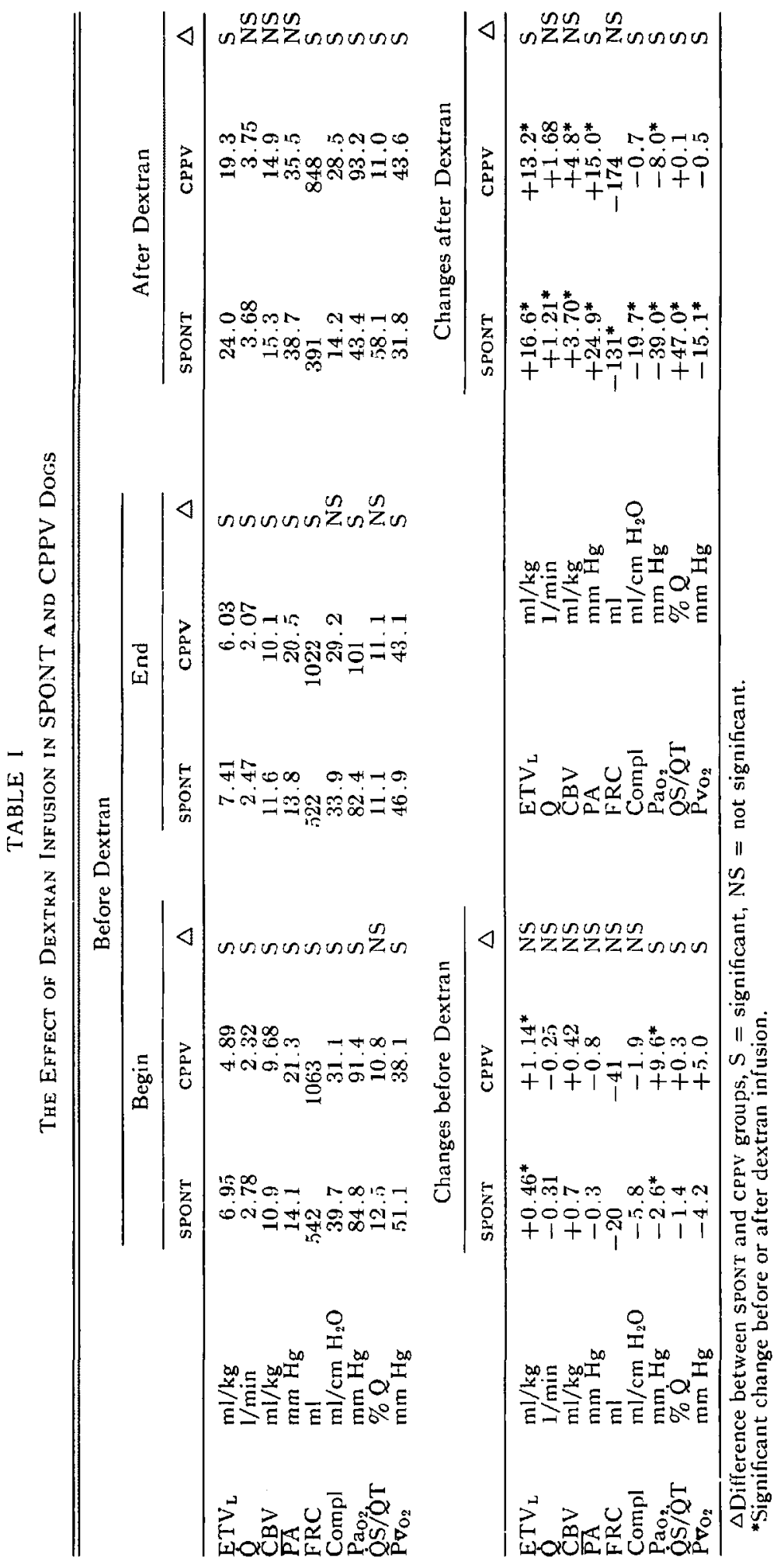


connected to a wedge spirometer. Pulmonary arterial pressure (PAP), systemic arterial pressure, airway pressure, oesophageal and plethysmograph pressures were monitored by Statham transducers on a Beckman 6 Channel Recorder. FRC was measured by a method of DuBois. ${ }^{11}$ Arterial and mixed venous blood samples were analysed for oxygen and carbon dioxide tensions on Clarke and Severinghaus electrodes (Radiometer-Copenhagen). Expired gas was analysed by an infrared capnograph and a paramagnetic oxygen analyser. Haemoglobin was measured by colorimetry. Oxygen consumption $\left(\dot{\mathrm{V}}_{\mathrm{O}_{2}}\right)$, alveolar ventilation $\left(\dot{\mathrm{V}}_{\mathrm{A}}\right)$, dead space $\left(\mathrm{V}_{\mathrm{D}} / \mathrm{V}_{\mathrm{T}}\right)$ and shunt $(\dot{\mathrm{Q} S} / \dot{\mathrm{Q} T})$ were calculated from standard equations ${ }^{12-15}$ allowing correction for temperature and pressure changes.

Cardiac output $(\dot{Q})$, central blood volume $(\mathrm{CBV})$ and extravascular thermal volume $\left(\mathrm{ETV}_{\mathrm{L}}\right)$ were calculated from thermal and electrical conductivity changes in the aorta, following a bolus injection of 3 per cent sodium chloride at room temperature into the pulmonary artery. $\mathrm{ETV}_{\mathrm{L}}$ was used to monitor the volume of oedema in the lung. The method has been previously reported in detail."

Several measurements established a baseline for each dog. Pulmonary oedema was then induced by a rapid infusion of dextran 40 into the right femoral vein. Fifteen dogs breathed spontaneously during the infusion and eight others were ventilated by the Harvard Pump and $16 \mathrm{~cm} \mathrm{H}_{2} \mathrm{O}$ of end expiratory pressure (CPPV) was applied. After the oedema was induced, CPPV was discontinued in five dogs which were then allowed to breathe spontaneously. Seven other dogs initially breathing spontaneously during the dextran infusion were later provided with CPPV. Mean volume and rate of dextran infusion were the same in spontaneously breathing and CPPV groups.

All measurements were repeated at 5 to 10 -minute intervals. Twenty to thirty paired measurements of $\mathrm{ETV}_{\mathrm{L}}, \mathrm{CBV}, \dot{\mathrm{Q}}, \mathrm{FRC}$, Compliance, $\dot{\mathrm{Q}} \mathrm{S} / \dot{\mathrm{Q}} \mathrm{T}$ and $\dot{\mathrm{V}}_{\mathrm{O}, 2}$ were made during each experiment. Only initial and final values both before and after the dextran infusion will be presented. Initial and final values before and after the use of CPPV will also be shown for all dogs where the ventilation was changed. Data from individual dogs were meaned and the differences between spontaneously breathing (SPONT) and ventilated (CPPV) group were examined by the Student's $t$ test. Changes significant at $\mathrm{P} \leqslant 0.5$ will be discussed.

At the end of each experiment the trachea was occluded at FRC and the heart was stopped by injecting $10 \mathrm{ml}$ of saturated $\mathrm{KCl}$ into the pulmonary artery. The chest was then opened and the pulmonary vessels ligated. The lungs were removed. and their appearance, volume and weight recorded. Pulmonary oedema was then measured directly using lung weight after dessication.

\section{Results}

The effect of CPPV on the development of oedema and lung function is summarized in Table I. A small but significant rise of ETV $\mathrm{I}_{\mathrm{L}}$ was seen in both groups prior to the infusion of dextran. This rise was approximately twice as fast in the CPPV group as in the spontaneously breathing dogs. Following the dextran infusion, oedema accumulated more rapidly in the spontaneously breathing dogs. The formation of oedema was not linear. The $\mathrm{ETV}_{\mathrm{L}}$ rise was initially slow but then it 

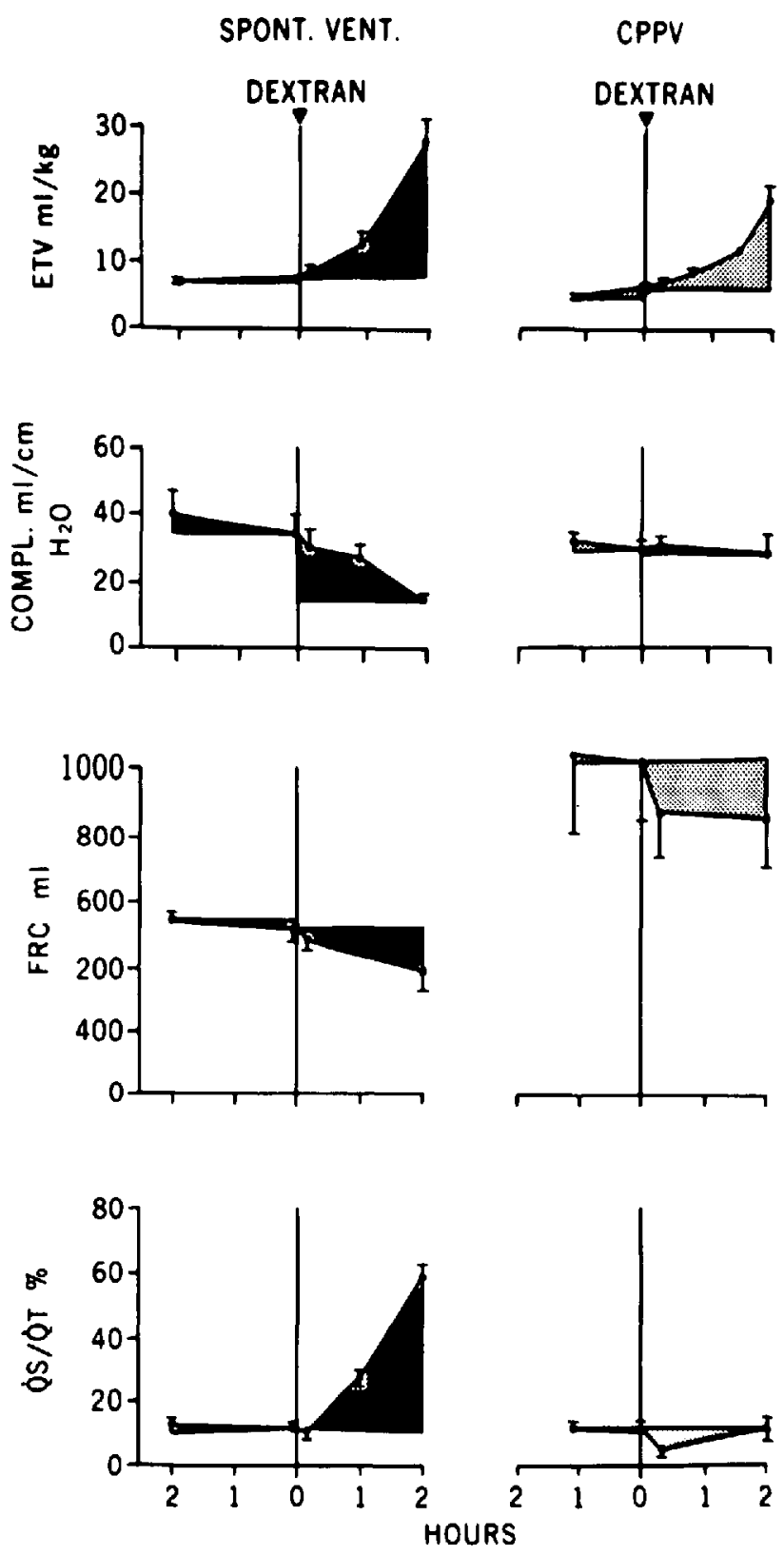

Figure 1. Dextran infusion in spontaneously breathing dogs and in dogs ventilated with CPPV. Vertical line marks beginning of the infusion. Dots represent mean values and bars show \pm one standard deviation.

rapidly accelerated, with the fastest rate of oedema formation at the end of each experiment (Figure 1). The application of CPPV prior to dextran infusion resulted in a small and instant drop of $\mathrm{ETV}_{\mathbf{L}}$, coinciding with a drop in the cardiac output (Table II). Once severe oedema was induced, ETV $_{L}$ continued to rise, regardless of application or removal of CPPV. 


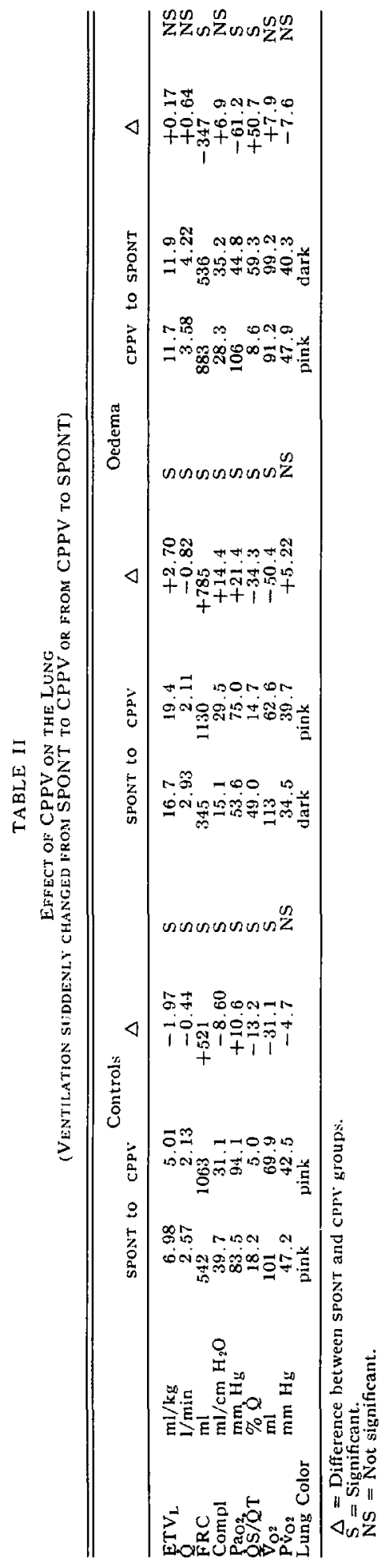


SPONT. VENT.

CPPV

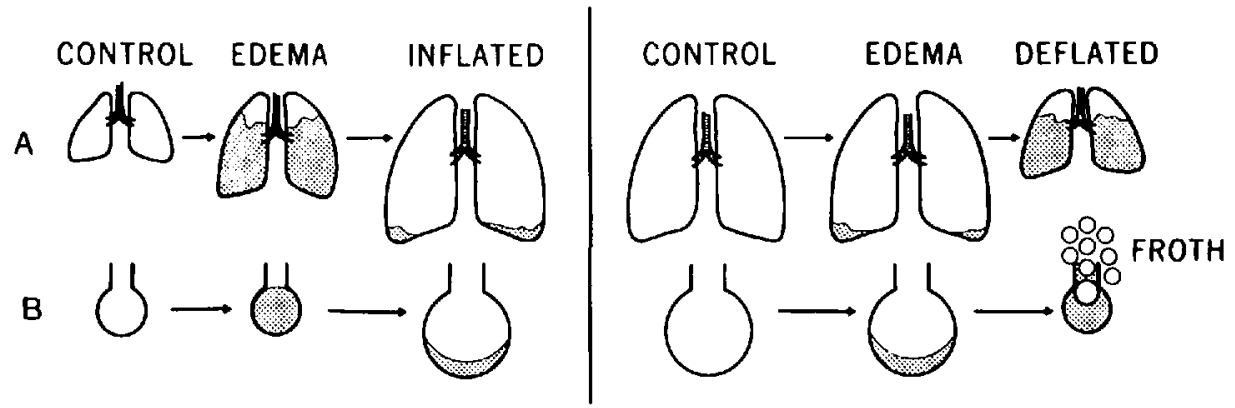

Figure 2-A. The effect of ventilation on gross appearance of the lung. Formation of oedema was associated with extensive hepatization of lung tissue. Inflation of oedematous lung instantly reversed hepatization without reducing volume of oedema. Application of CPPV prevented hepatization of lung in oedema. Removal of CPPV led to rapid hepatization and outflow of froth.

FIGURE 2-B. Schematic drawing of pulmonary alveolus. Single deep inflation forced some gas into flooded alveolus. Application of CPPV overdistended alveolus and prevented complete flooding. Removal of CPPV decreased alveolar size and resulted in sudden and complete filling of the alveolus.

Prior to dextran infusion cardiac output and central blood volume were lower, whereas PAP was higher in the CPPV dogs (Table I). After dextran infusion the cardiac output, central blood volume and PAP were elevated to the same extent in both groups. When the infusion was stopped, cardiac output, central blood volume and PAP begin to decline whereas oedema formation steadily accelerated in both groups.

The FRC of the CPPV dogs was approximately twice that of the spontaneously breathing animals. No change of FRC was detected prior to dextran but FRC fell after infusion in both groups (Table I and Figure 1). Application of CPPV resulted in an instant rise of FRC; its removal was always followed by a rapid and then a more gradual decline of FRC values (Table II).

Higher compliance was found in spontaneously breathing dogs prior to dextran infusion. This rapidly deteriorated once the oedema started to accumulate. With CPPV no change of compliance was seen even in severe oedema (Table I and Figure 1). When CPPV was applied late in oedema, compliance improved, although the amount of oedema did not change. The removal of CPPV in oedema resulted in an instantaneous rise of compliance (not significant) which then fell rapidly (significant) (Table II).

At postmortem examination the lungs of the spontaneously breathing dogs in oedema were heavier and larger than in the controls (Figure 2). Dependent lobes were dark and liver-like in consistency (hepatization). The extent of hepatization correlated with the final ETV $_{\mathrm{L}}$. The dark lobes contained serosanguinous fluid but no gas. The upper lobes were aerated pink and over-distended. In contrast the lungs of the CPPV dogs were bulky and uniformly pink. When CPPV was removed they developed dark areas in the dependent lobes and the picture was almost identical with the hepatization seen in the spontaneously breathing dogs. A single deep inflation instantly transformed dark, meaty lobes into pink and 
aerated normal-appearing lung. When the inflating pressure was removed, affected lobes resumed their previous liver-like appearance. A single deep inflation or the removal of CPPV in oedema usually produced an outflow of froth. This was observed in living animals as well as in the excised lung specimens. Spontaneously breathing dogs rarely developed froth even in severe pulmonary oedema.

Decline of $\mathrm{Pa}_{\mathrm{O}_{2}}$ coinciding with a rise of pulmonary shunt was seen in all spontaneously breathing dogs in oedema. Occasionally up to 80 per cent of the total cardiac output was shunted making these dogs severely hypoxemic. Shunt correlated well with the rising $\mathrm{ETV}_{\mathrm{L}}$ value and with the extent of pulmonary hepatization. In contrast, shunt in CPPV dogs remained small even in severe oedema and $\mathrm{Pa}_{\mathrm{O}_{2}}$ seldom fell below $80 \mathrm{~mm} \mathrm{Hg}$ (Table I). When CPPV was suddenly applied in oedema, shunt improved and $\mathrm{Pa}_{\mathrm{O}_{2}}$ rose (Table II). This change was instantaneous in some dogs but more gradual in others. The best results were seen when a single deep inflation preceded the use of continuous positive pressure. Although $\mathrm{Pa}_{\mathrm{O}_{2}}$ was improved, it never returned to pre-oedema values. The removal of CPPV in oedema produced a rapid rise in shunt and a profound drop of $\mathrm{Pa}_{\mathrm{O}_{2}}$.

The sudden application of CPPV always resulted in a drop of cardiac output and systemic hypotension (Table II). When CPPV was used, 2 out of 15 dogs died quickly from circulatory failure despite an improvement in arterial oxygen tension. Mechanical ventilation also resulted in a significant reduction in oxygen consumption. This drop was greater in severe oedema than in controls. Although the changes were not significant, mixed venous oxygen tension declined when CPPV was used in controls, rose when CPPV was applied in severe oedema and fell when CPPV was removed in oedema.

\section{Discussion}

\section{The Effect of CPPV on the Formation of Pulmonary Oedema}

The beneficial effect of elevated airway pressure on lung function in pulmonary oedema has been recognized for several years. The instantaneous improvements in radiological changes, $\mathrm{Pa}_{\mathrm{O}_{2}}$, shunt and pulmonary compliance led to speculation that oedema fluid is forced from the alveoli back into pulmonary circulation. ${ }^{1,4}$

Although we cannot comment on the prolonged use of CPPV our data suggest that the sudden elevation of airway pressure reverses pulmonary hepatization, improves $\mathrm{Pa}_{\mathrm{O} y}$, shunt and compliance without reducing the amount of oedema within the lung. CPPV slowed down but did not prevent the formation of oedema. We do not know why the dextran induced rise in ETV $_{\mathrm{I}}$ was slower in the CPPV group. The volume of dextran and rate of infusion were the same in both groups. Pulmonary arterial pressures after dextran were also comparable, however, since the CPPV dogs had higher pulmonary artery pressures before dextran, the elevation brought on by dextran overload appeared to be relatively smaller. Therefore, the dextran induced rise of trans-capillary pressure was smaller in the CPPV group.

Since $\mathrm{ETV}_{\mathrm{L}}$ values depend to some extent on pulmonary perfusion ${ }^{16,17}$ the question arises whether lower $\mathrm{ETV}_{\mathrm{L}}$ values seen in ventilated dogs merely reflect 
a lower cardiac output in this group. Although this could be a factor in control dogs, dextran infusion grossly elevated cardiac output in both groups and it is unlikely that any oedema escaped detection due to incomplete perfusion of the lung. In vitro measurements showed good correlation between final $\mathrm{ETV}_{\mathrm{L}}$ values and the lung extravascular water measured directly in both groups at the end of each experiment." We therefore believe that lower ETV $_{\mathrm{L}}$ values in the CPPV group after dextran represent smaller quantities of oedema in these dogs.

It was interesting to find a small but consistent rise of ETV $_{\mathrm{L}}$ in anaesthetized dogs prior to the dextran infusion. No change of pulmonary artery pressure was seen and cardiac output declined slightly during this period. Formation of oedema in anaesthetized controls was faster in the CPPV group and it appears as if CPPV hastens formation of oedema in the healthy lung. Whether this is caused by stretching of alveolar membranes or by interference with bronchial or lymphatic circulation is not known.

\section{The Effect of CPPV on Mechanics of Ventilation}

A decline of FRC in pulmonary oedema has been previously reported. ${ }^{18}$ Airway closure, vascular congestion or alveolar oedema were suggested as the mechanism. A fall of FRC should be expected as pulmonary gas is gradually displaced by expanding central blood volume and oedema fluid.

Following the infusion of dextran a small decline of FRC was observed in both groups. This decline coincides with the rise of ETV $\mathrm{L}_{\mathrm{L}}$ and CBV and was almost identical in the spontaneously breathing and CPPV groups of dogs. The overall decline of FRC was smaller than would be expected from the combined increases in ETV $_{\mathrm{I}}$ and CBV values. This suggests that while some alveoli are flooded with oedema, empty alveoli compensated for the FRC lost by expanding their volume. The volume of the oedematous lung (measured by fluid displacement) was considerably increased. As expected, the application of CPPV produced a large increase in FRC and the reverse was seen when CPPV was discontinued.

In the normal lung, increased airway pressure distends aerated alveoli. In oedema, however, application of CPPV reverses hepatization of lung tissue. Some alveoli completely flooded with transudate become aerated and FRC also increases by recruitment of previously flooded alveolar units ${ }^{2,18}$ (Figure 2).

The formation of oedema was associated with a decline of pulmonary compliance in all spontaneously breathing dogs. This was not the case when oedema was induced in dogs ventilated by CPPV. Despite the large volume of oedema present, pulmonary compliance remained high. The lung remained uniformly aerated and gross hepatization was never observed. It therefore appears that pulmonary compliance reflects aeration of alveolar units rather than the quantity of oedema within the lung. This point is further illustrated by the improvement of compliance despite the rise of ETV $\mathrm{E}_{\mathrm{r}}$ when the CPPV is suddenly applied in oedema. By forcing some gas into previously flooded alveoli, total surface area is enlarged with a resulting improvement in lung compliance. This beneficial effect of CPPV is offset to some extent by over-distention of empty alveoli. Sudden removal of the high airway pressure can temporarily improve compliance simply by removing an overdistention factor. Actual behaviour of compliance will depend on the balance between overdistention and aeration of the flooded alveoli. 


\section{The Effect of CPPV on Gas Exchange}

It is well recognized that the major defect in gas exchange in pulmonary oedema is the increase in pulmonary shunt. ${ }^{19}$ In some of our dogs the shunted fraction rose to 80 per cent of the total cardiac output, but most dogs were sacrificed before they reached this stage. The degree of shunt correlated well with the extent of pulmonary hepatization. The lungs of the spontaneously breathing dogs in oedema were extensively hepatized and the shunted fraction of the cardiac output was high. The lungs of the CPPV dogs remained pink and uniformly aerated even in severe oedema and the shunt remained low. A single deep inflation or application of CPPV did not decrease the volume of oedema, but did improve aeration of the flooded alveoli and improved pulmonary shunt. This experience correlates well with others who showed an almost instantaneous rise of $\mathrm{Pa}_{\mathrm{O}_{2}}$ following the application of CPPV. ${ }^{2-4}$

Although shunt and $\mathrm{Pa}_{02}$ improved, a drop of cardiac output on sudden application of CPPV was of such magnitude that oxygen transport was not significantly improved. Other investigators have pointed out this problem., ${ }^{3,4,6,20,21} \mathrm{~A}$ gradual rise in airway pressure led to a less profound depression of cardiac output and the best results were seen when one or two deep inflations preceded gradual application of CPPV. The application of CPPV in severe oedema did not improve $\mathrm{Pv}_{\mathrm{O}_{2}}$ or $\mathrm{O}_{2}$ transport while the use of CPPV during oedema induction clearly prevented their deterioration. While spontaneously breathing dogs became moribund within two hours after dextran, the CPPV dogs did remarkably well up to four hours afted dextran infusion. Once the airway pressure was lowered the animals died quickly.

The rising rate of oedema formation suggests that even alveoli distended by CPPV will finally fill up with fluid. In this respect the use of CPPV, however effective, must not be substituted for other methods dealing more directly with the formation of oedema or with the removal of alveolar fluid.

\section{SUMMARY}

The effect of continuous positive pressure ventilation was studied in 23 dogs in whom pulmonary oedema was induced by rapid intravenous infusion of dextran 40. CPPV slowed but did not prevent the formation of oedema.

CPPV prevented or reversed the formation of liver-like areas in the dependent lobes, maintaining the oedematous lung compliant and aerated. This led to a reduction of shunt and an increase in $\mathrm{Pa}_{\mathrm{O}_{2}}$. The use of CPPV decreased cardiac output and body oxygen consumption. Mixed venous oxygen tension was higher in dogs ventilated by CPPV and these dogs tolerated fulminant frothy oedema without distress.

\section{RÉSUMÉ}

Ce travail avait pour but d'étudier les effets d'une ventilation à pression positive constante chez 23 chiens en cedème pulmonaire (causé par l'infusion rapide de Dextran 40). La pression positive continuelle a ralenti mais n'a pas empêché la formation d'œdème.

Elle a aussi empêché ou rendu réversible la formation de zones hépatisées 
dans les lobes déclives du poumon, tout en le maintenant compliant et aéré. Conséquemment, on a assisté à une diminution du shunt et une augmentation de la $\mathrm{Pa}_{\mathrm{O}_{2}}$. La pression positive constante a diminué le débit cardiaque et la consommation d'oxygène. La pression partielle de l'oxygène dans le sang veineux mixte était plus élevée chez les chiens ventilés sous PEEP et ces chiens supportaient sans trop de détresse un œè̀me pulmonaire suraigu.

\section{ACKNOWLEDGMENTS}

This project was supported by an MRC Fellowship Grant.

The authors gratefully acknowledge considerable help from St. Michael's Hospital technicians and secretaries in conducting the experiments and preparing the manuscript.

\section{REFERENCES}

1. Ashanugh, D.G., Petry, T.L., Bigelow, D.B., \& Harris, T.M. Continuolis positive-pressure breathing (CPPB) in adult respiratory distress syndrome. J. Thor, and Cardiovasc. Surg. 57: 31 (1969).

2. Sugerman, H.J., Olofsson, K.B., Pollock, T.W., Agnew, R.F., Rogers, R.M., \& Miller, L.D. Continuous positive end-expiratory ventilation (PEEP) for the treatment of diffuse interstitial pulmonary edema. J. Trauma. 12: 263 (1972).

3. Kumar, A., Falke, K.J., Geffin, B., Aldridce, C.F., Laver, M.B., Lowenstein, E., \& Pontoppidan, $H$. Continuous positive-pressure ventilation in acute respiratory failure. N.E.J.M. 283: 1430 (1970).

4. Lutch, J.S. \& Murray, J.F. Continuous positive-pressure ventilation: effects on systemic oxygen transport and tissue oxygenation. Ann. Internal Med. 76: 193 (1972).

5. McIntyre, R.W., Laws, A.K., \& Ramachandran, P.R. Positive expiratory pressure plateau: improved gas exchange during mechanical ventilation. Can. Anaesth. Soc. J. 16: 477 (1969).

6. PetTY, T.L., NetT, L.M., \& Ashbaugh, D.G. Improvement in oxygenation in the adult respiratory distress syndrome by positive end-expiratory pressure (PEEP). Resp. Care 16: 173 (1971)

7. Colgan, F.J. \& Marocco, P.P. The cardiorespiratory effects of constant and intermittent positive pressure breathing. Anaesthesiology 36: 444 (1972).

8. Staub, N.C., Nagano, H., \& Pearce, M.L. Pulmonary edema in dogs, especially the sequence of fluid accumulation in the lungs. J. Applied Physiol. 22: 227 (1967).

9. Noble, W.H., Obdrzalek, J., \& Kay, J.C. A new technique for measuring pulmonary edema. J. Applied Physiol. 34: 508 (1973).

10. Milic-Emili, J., Mead, J., Tuhner, J.M., \& Glauser, E.M. Imiproved technique for estimating pleural pressure from esophageal balloons. J. Applied Physiol. 19: 207 (1964).

11. Dubors, A.B., Botelho, S.Y., Bedell, G.N., Marshall, R., \& Comroe, J.H. Jr. A rapid plethysmographic method for measuring thoracic gas volume: a comparison with a nitrogen washout method for measuring functional residual capacity in normal subjects. J. Clinical Investig. 35: 322 (1956).

12. Kuwabara, S. \& Duncalf, D. Effect of anatomic shunt on physiologic deadspace-to-tidal volume ratio - a new equation. Anaesthesiology $31: 575$ (1969).

13. Comboe, J.H., Jr., Forster, R.E., Dubois, A.B., Briscoe, W.A., \& Carlsen, E. The lung: clinical physiology and pulmonary function tests. 2nd edition. Chicago: Year Book Medical Publishers Inc. (1962).

14. Duncalf, D. \& Kuvabara, S. Computer analysis of respiratory data. Anaesthesia and Analgesia 50: 719 (1971).

15. Kelman, G.R. \& NunN, J.F. Nomograms for correction of blood $P_{n_{y}}, P_{c o g}, p H$ and base excess for time and temperature. J. Applied Physiol. 21: 1484 ( 1966).

16. Kгrк, B.W. Effect of alterations in pulmonary blood flow on lung-exchangeable water in the dog. J. Applied Physiol. 27: 607 (1969).

17. Levine, O.R., Mellins, R.B., \& Senion, R.M. Extravascular lung water and distribution of pulmonary blood flow in the dog. J. Applied Physiol, 28: 166 (1970). 
18. Falke, K.J., Pontoppidan, H., Kumar, A., Leith, D.E., Geffin, B., \& Laver, M.B. Ventilation with end-expiratory pressure in acute lung disease. J. Clin. Invest. 51: 2315 (1972).

19. Sam, S.I., Longacher, J.W., Jr., Davis, R.K., Banerjez, C.M., Davis, W.M., \& WoodDELL, W.J. Pulmonary gas exchange during induction of pulmonary edema in anaesthetized dogs. J. Applied Physiol. 19: 403 (1964).

20. Lenfant, C. \& Howell, B.J. Cardiovascular adjustments in dogs during continuous positive pressure breathing. J. Applied Physiol. 15: 425 (1960).

21. Philbin, D.M., Patterson, R.W., \& Baratz, R.A. Continuous positive pressure ventilation and oxygen delivery. Brit. J. Anaesth. 44: 667 (1972).

22. Woods, R., Rogers, R.M., Sugerman, H.J., \& Tantum, K.M. An inexpensive continuous positive end-expiratory pressure (PEEP) adaptor for positive pressure respirators. Chest. 61: $376(1972)$. 